\title{
ASSINATURAS QUE EMERGEM DA COMÉDIA DANTESCA
}

\author{
Jackeline Maria Beber Possamai* \\ Universidade Federal de Santa Catarina
}

Resumo: Giorgio Agamben, ao elaborar o livro Signatura Rerum (2008), afirma ser possível investigar o passado, para chegar ao paradigma, definido como um conhecimento analógico. Agamben disserta também sobre a assinatura, a linguagem do mundo, da qual se percebe o espírito interior das coisas em sua exterioridade, além de definir a arqueologia filosófica, momento em que os saberes e os discursos são constituídos. Na esteira de Michel Foucault, o filósofo italiano argumenta que a "arqueologia é a ciência das ruínas, prática, que indaga a história não pela origem, mas como a emergência do fenômeno". (AGAMBEN, 2008, p. 121). Neste caso, da obra literária emergem fenômenos e indícios, a exemplo da Divina Comédia, de cujo poema surgem personagens da mitologia grega, filósofos e poetas, dentre os quais, o mantuano Virgílio, e outras personagens. Essas singularidades, identificadas na Comédia, são objeto para um possível entrecruzamento com o conceito de assinatura, de Agamben.

Palavras-chave: Literatura. Divina Comédia. Arqueologia. Indícios. Assinatura.

A arqueologia [...] não é nada além e nada diferente de uma reescrita. (FOUCAULT, 2014. p. 158)

\section{Introdução}

O texto em epígrafe é de Michel Foucault, cuja abordagem arqueológica tem por base a história do pensamento, do saber, da filosofia, da literatura, áreas que parecem "multiplicar as rupturas e buscar todas as perturbações da continuidade". (FOUCAULT, 2014, p. 6). Os estudos, voltados à filosofia e às ciências, constituem objeto para que Giorgio Agamben elaborasse o Signatura Rerum (2008), livro que contém o conceito de paradigma, definido como um conhecimento que não é indutivo e nem dedutivo, mas analógico, que se move de singularidade em singularidade. Esse fazer de Agamben neutraliza a dicotomia entre o geral e o particular, substitui a lógica dicotômica para "um modelo analógico bipolar", ou

Esta obra está licenciada sob uma Creative Commons - Atribuição 4.0

\footnotetext{
* Doutoranda em Literatura pela UFSC. Mestrado em Literatura (2007). Especialização em Educação a Distância: Gestão e Tutoria (2012). Graduação em Letras-Português (2004) e Língua e Literatura Italiana (2002). É docente do Curso de Letras na modalidade a distância - UNIASSELVI - Centro Educacional Leonardo da Vinci. E-mail: jackelinetimbo@gmail.com.
}

Anu. Lit., Florianópolis, v. 22, n. 2, p. 53-61, 2017. ISSNe 2175-7917 
seja, o paradigma, uma terceira via, é um método de análise que se configura do particular para o particular.

Desse modo, Agamben, no livro em questão, vai tecendo reflexões sobre o paradigma, a teoria das assinaturas e a arqueologia filosófica. Com base nesses apontamentos, pretende-se, neste artigo, refletir sobre os conceitos delineados por Agamben, entrecruzandoos com algumas "particularidades" identificadas na Divina Comédia (1998), de Dante Alighieri, tendo em vista alguns fenômenos presentes nesse poema. $\mathrm{O}$ conceito de assinatura ou arché sustenta as reflexões que são pretendidas neste artigo, a fim de identificar saberes ou delimitar conexões, especialmente as encontradas no canto IV do Inferno e nos cantos VII e XXII do Purgatório.

Há que se enfatizar que o canto IV, por meio do Limbo, expressa algumas particularidades, como o saber teológico dos não batizados e dos que não professaram a fé cristã, razão pela qual Dante-autor "edificou" um castelo a fim de "abrigar" os pagãos virtuosos, representados pelos escritores e pensadores da Antiguidade clássica.

\section{A linguagem das assinaturas}

Para encontrar o paradigma, Agamben (2008, p. 74) expõe um método que leva em conta a singularidade, algo quase imperceptível e também afirma que a assinatura é a linguagem do mundo, que pode ser decifrada, percebida e compreendida, é o "lugar onde o gesto de ler e o gesto de escrever invertem sua relação e entram em una zona do indizível". Por meio da assinatura, pode-se perceber o espírito interior das coisas em sua exterioridade. É por assim dizer "uma espécie de poder latente de significação que ultrapassa os limites de uma significação, predeterminada pelo sistema linguístico, tornando-o verdadeiramente inteligível e eficaz". (AGAMBEN, 2008, p. 82).

No capítulo final do referido livro, encontramos o que Agamben define como arqueologia filosófica, momento em que os saberes e os discursos são constituídos. Tal conceito também é baseado em Foucault, para o qual o poder se estabelece no cruzamento com a história, e, mais especialmente, nas práticas discursivas. No texto As palavras e as coisas (2010), Foucault enfatiza a genealogia do saber, estabelecendo uma metodologia que verifica o conhecimento humano, permitindo a construção do pensamento. Nessa esteira, Giorgio Agamben afirma que a "arqueologia é a ciência das ruínas, prática, que indaga a história não pela origem, mas como a emergência do fenômeno". (AGAMBEN, 2008, p. 121).

Por essa perspectiva, a literatura é um campo de emergência de fenômenos, por conter em si a autoria, a invenção, a linguagem elaborada, e por representar uma forma de 
conhecimento, objeto de estudo da arqueologia. Assim, a Divina Comédia poderia ser analisada pelo viés arqueológico, pois está assentada nos indícios do mundo de Dante e nos fatos da sociedade italiana do século XIII. Este autor conciliou diferentes relações, diversos elementos, trazendo, para o nosso tempo, a percepção do tempo em que foi escrita, a Idade Média,

Quando Dante elaborou o Inferno, o Purgatório e o Paraíso abordou questões religiosas, populares, personagens da mitologia clássica e da história, filósofos, escritores, pessoas de suas relações e desafetos, papas, santos, pecadores e muitas alegorias. Para Alfredo Bosi (1977, p.163), o olho do poeta exerce papel importante na narrativa, porque "ordena as figuras no todo e atribui a cada uma a sua melhor posição dentro de uma hierarquia prévia de valores".

Hierarquia identificada e que se dá pelo fato do personagem-Dante iniciar sua jornada pelo inferno, ou seja, do nível mais baixo para o mais alto. Assim, em companhia de Virgílio, ambos chegam à selva de espíritos, no Limbo, atraídos por um feixe de luz, que atenua a escuridão do inferno, vindo de uma edificação semelhante a um castelo. $\mathrm{Na}$ caminhada em direção à luz, o viator-Dante ouve uma voz jubilosa, que se origina das quatro sombras, representadas por Homero, Horácio, Ovídio e Lucano. O primeiro dos poetas, o interlocutor, é Homero, que convida os demais a saudarem Virgílio, grande escritor que havia partido e estava retornando.

É fato que Virgílio, no início da Comédia, foi reconhecido por Dante como seu “mestre e autor". Sobre isso, Benedetto Croce (1948, p. 68) afirma que:

no primeiro canto as palavras dirigidas por Dante a Virgílio tremem de comoção, ao encontrarem-se, ouve a voz do antigo poeta que estava, há muito tempo, em grande parte da sua vida interior, mestre de sabedoria, mestre do belo estilo, assim longe no tempo, assim perto em todos os seus pensamentos.

Virgílio é lembrado principalmente pela autoria da Eneida, a epopeia que trata da fundação de Roma e tem como personagem Enéas, guerreiro troiano, incumbido da fundação da nova pátria, na região do Lácio. As aventuras de Enéas também se relacionam com o seu vagar pelo Mar Mediterrâneo, como ocorre na Odisséia, quando Ulisses é posto a realizar tarefas semelhantes até retornar a Ítaca. A segunda parte do texto está ligada à Ilíada, uma vez que o suporte é a guerra de Tróia. Virgílio era considerado símbolo da sabedoria moral, "mestre do estilo sublime, [...] a suprema corporificarão da razão - uma razão poética, que se apoderava da realidade e transformava em visão". (AUERBACH, 1997, p. 78). Além disso, esse poeta sugeriu, através de sua obra, "a vinda de uma nova idade para a humanidade", 
(FALLANI et al, 1993, p. 30). Virgílio foi um prenunciador da fé, representada pela vinda do salvador do cristianismo, embora ele mesmo não a tenha vivenciado. O Canto XXII do Purgatório faz referência a este fato. Trata-se da cena em que Dante e Virgílio encontram o poeta Estácio. Este último credita o seu valor como escritor à literatura de Virgílio, atribuindo-lhe o seu progresso espiritual e o primeiro encaminhamento à fé. Estácio afirma:

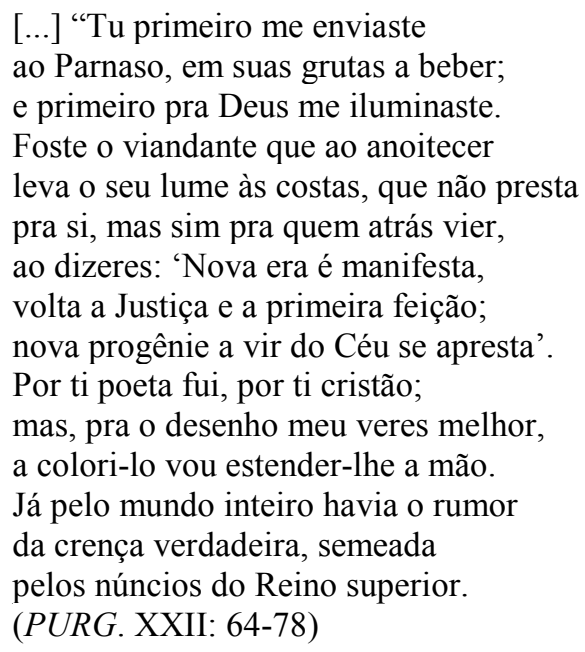

Essas interpretações forneceram a base para o título medieval de um Virgílio précristão. Sobre essa questão, Sapegno (1986) afirma que os escritos virgilianos falam de renovação e refletem o sentimento de uma nova era, uma profecia sobre o nascimento do Redentor.

Outro episódio relatado por Virgílio se refere ao canto VII do Purgatório ao encontrar seu conterrâneo Sordello em companhia de Dante-peregrino. O poeta-guia faz alusão ao Limbo quando diz estar num lugar desprovido de martírio, junto àqueles que não viveram as virtudes teologais:

\footnotetext{
Não por fazer perdi - por não fazer a vista do alto Sol, ao qual não miro, por muito tarde o vir a conhecer. Não é de penas lá nosso retiro, mas só de escuridão, onde o lamento, não como grito soa, mas só suspiro. De todo infante, é lá esse o lamento, pelas garras da morte antes colhido de poder ser de humana culpa isento; e lá estou eu co'os que não têm vestido as três virtudes, mas sem vício as outras conheceram e as têm cumprido. (PURG. VII: 25-36).
}

Ao que parece, Dante assumiu a mentalidade do cristianismo medieval em que a salvação passava pela fé e pelo batismo, imprimindo um caráter divino à figura de Jesus, o 
apelo à salvação e à imortalidade. É pela ausência de dois elementos - fé e batismo - que as almas do Limbo permanecem numa condição suspensa, num “desejo contínuo, mas ineficaz e eternamente igual o seu existir, porque são sabedoras da existência de uma felicidade suprema que não possuem meios para alcançá-la”. (FALLANI et al 1993, p. 53).

No entanto, lá não figuram somente os infiéis, uma vez que, ao passar pelo Limbo, Dante-personagem tem a confirmação da fé assumida pelos patriarcas bíblicos, ao saber que Jesus desceu ao inferno e resgatou Adão, Abel, Noé, Moisés, Davi, Abraão, Israel, Raquel e muitos outros abençoados. A descida de Cristo ao Limbo representa seu encontro com os justos do Antigo Testamento, que aguardavam, no lugar sombrio, a vinda do salvador e sua redenção para serem libertados. Segundo Sapegno, (1986), Dante pensou provavelmente numa representação de um Cristo triunfante, como aquele descrito nos quadros e mosaicos medievais, onde o filho de Deus aparece coroado por uma auréola, ou como fez Giotto de Bondone, ao pintar a "Descida ao Limbo", que se encontra na Alta Pinacoteca, em Munique.

Poder-se-ia dizer que a ilustração de Giotto também contém uma assinatura de Dante, porque ela "não expressa simplesmente uma relação semiótica entre um significado e um significante, mas a desloca em outro campo, em uma nova rede de relações pragmáticas e hermenêuticas" (AGAMBEN, 2008, p. 54), ou seja, para além da representação pictórica, há no poema em questão uma respresentação literária. Além disso, no âmbito da Divina Comédia, representa uma verdade salvífica e dogmática, "que leva aos homens a redenção e a vida”. (AGAMBEN, 2009, p. 72). O poeta possuía subsídios para concebê-lo, com liberdade de movimento, criando o Limbo poeticamente não menor daquele dos pintores ou dos ambientes litúrgicos. (FALLANI, 1976).

No Purgatório, Virgílio conversa com Estácio e menciona Homero, personalidade literária que ocupou, na vida do seu povo, um lugar de destaque. Não por acaso, vários se inspiram no "poeta soberano", a águia que elevou a poesia mais que todos. Em perspectiva com o conceito de assinatura, a pintura "Parnaso - Apolo e as Musas", de Rafaello Sanzio, na Stanza della Segnatura, Museu do Vaticano, reitera a conversa do Purgatório, quando Virgílio cita que: “Estamos [...], co' aquele grego,/ das Musas mais nutrido que ninguém,/ no primo giro do cárcere cego./ lá sempre discorremos sobre o monte/ onde as nossas nutrizes têm achego. (PURG. XXII: 101-105). Virgílio relata que, no Limbo, os poetas clássicos discorrem sobre o Parnaso, uma referência ao monte da Fócida, na Grécia, consagrado a Apolo e às musas, ou a residência mitológica da poesia e da música.

Outro episódio do Limbo honra a poesia, já que Dante-viator fora convidado para 
integrar o grupo dos grandes escritores, o "sexto entre tanto saber." (INF. IV: 102). Significa dizer que ele, como escritor, teve a capacidade de aderir ao "belo grupo de escritores", soube imitar os valores da razão, e foi receptivo à grandeza intelectual, motivos pelos quais sua poética 'invade' o cenário literário da Idade Média e também o posterior a ela.

Foi também nesse sentido que Dante concebeu o "Nobre Castelo", "morada" dos que ele define como "honrosa gente", a exemplo de Virgílio e outros escritores, pensadores e filósofos gregos. O peregrino descreve que para acessarem o castelo, local que denota distinção, ele e os demais atravessam o riacho "como terra dura". (INF. IV: 109), e que, segundo Sapegno (1986), poderia representar a eloquência, a facilidade em lidar com a poesia. Depois adentram as sete portas, que representam as sete artes liberais: gramática, dialética, retórica, música, aritmética, geometria e astronomia.

Essa simbolização evidencia marcas e rastros, que traduzem todo conhecimento dos pensadores e filósofos, o hiato "onde se situam as assinaturas", a arché. (AGAMBEN, 2008, p. 82). Aquelas portas seriam também as quatro virtudes morais: prudência, justiça, fortaleza e temperança e as três virtudes intelectuais: inteligência, ciência e sabedoria. Pelo viés da arché, as portas representam a possibilidade de reflexão sobre o conhecimento deixado à humanidade, ou no dizer de Massimo Cacciari, (2005, p. 15) é o confim, "a linha em que dois caminhos se tocam e se relacionam".

Assim, no Nobre Castelo, Dante teria reunido o saber de seu tempo, fazendo valer o espírito de sua consciência, fundamentado em pensadores e filósofos como Platão, Aristóteles, Sócrates, Euclides, Ptolomeu, Galeno e outros, também retratados na Stanza de Segnatura, Museu do Vaticano, por Rafaello Sanzio, sob o título de “A Escola de Atenas", uma assinatura na concepção de Agamben (2008, p. 149), a arché que garante "a inteligibilidade dos fenômenos históricos".

Outros personagens do Limbo também são ilustrados por Eugène Delacroix, na Cúpula da Biblioteca do Palácio de Luxemburgo, em Paris. Lá estão Horácio, Ovídio, Homero, Lucano, Virgílio, indícios do canto IV da Divina Comédia que aparecem na pintura de Delacroix, ponto de insurgência que desencadeia saberes que "são constituídos e têm lugar, por assim dizer, no não-lugar da origem. (AGAMBEN, 2008, p. 114). Esse não-lugar produz as relações ou tensões das quais emerge a assinatura.

As assinaturas delineadas até aqui reforçam os estudos sobre o método de Agamben, pela reflexão que elas desencadeiam, a exemplo de Homero, citado por Virgílio, no Purgatório, como "aquele grego" que recebera inspiração das musas mais do que os outros 
poetas, ideia de inspiração reiterada por Dante quando escolhe Beatriz, sua musa, para guiá-lo ao Paraíso.

O Nobre Castelo representa arte, poder, cultura e história, é símbolo de proteção e de transcendência. É ainda a representação da fillosofia e da sabedoria humana, um lugar iluminado e protegido, com caráter de revelação natural e de admiração. Dante, ao "edificar" o castelo, se inspira na literatura de Virgílio, dá testemunho da ascendência desse poeta e redesenha o Elísio pagão, ou o Panteon dos homens ilustres, afinal, como "devoto leitor da Eneida, imaginou os mortos no Elísio ou em alguma variação medieval desses campos afortunados”. (BORGES, 2000, p. 39. São recortes que autorizam [...] reduzir a diferença característica de qualquer começo, para retroceder, sem interrupção, na atribuição indefinida da origem; graças a ela, as novidades podem ser isoladas sobre um fundo de permanência, e seu mérito transferido para a originalidade. (FOUCAULT, 2014, p. 325)

E porque o discurso literário é terreno fértil para a arqueologia, por conter a historicidade, pode-se falar em enunciados diversos, como os encontrados em textos de Machado de Assis, por exemplo. Este autor escreveu, em terceira rima, o poema Última Jornada, com versos encadeados como os da Comédia, fazendo alusão aos versos do canto $\mathrm{V}$ do Inferno. São rastros ou assinaturas, pela alusão à estrutura poética e aos dois amantes, Paolo e Francesca, do poema dantesco.

\footnotetext{
E ela se foi nesse clarão primeiro, Aquela esposa mísera e ditosa; E ele se foi o pérfido guerreiro. Ela serena ia subindo a airosa, Ele à força de incógnitos pesares Dobra a cerviz rebelde e lutuosa. (ASSIS, 1997, p. 142)
}

Aqui importa enfatizar a emergência dos fenômenos: em Machado de Assis, na modernidade, e em Dante, na Idade Média, os quais têm em seus versos o encadeamento da terza rima e o casal de amantes que no Inferno, após a morte, são arrastados pela ventania. Com base na arqueologia, esses enunciados são práticas possíveis na literatura, porque seguem regras que definem o lugar do sujeito-enunciador e as condições de emergência. Trata-se de um retorno endereçado como subjetividade, uma escrita que busca capturar a essência de toda literatura, "e assim todos os seus fios convergem para a mais fina ponta singular, instantânea, e, contudo, absolutamente universal -, para o simples ato de escrever" (FOUCAULT, 2010, p. 416).

Desse modo, a literatura é sempre uma reescrita que traz ou desloca traços em uma 
dimensão de historicidade: sua história é a de suas leituras, segundo a perspectiva arqueológica de Agamben, que evidencia o presente, por meio da assinatura do passado.

No caso da Divina Comédia, a assinatura ou arché emerge no cruzamento entre alguns cantos, a partir de indícios encontrados nos seus versos; ou aparece na pintura ou ainda em textos contemporâneos, tornando inteligível o presente e o passado. Pelo seu caráter indelével, o vestígio possibilita a interpretação, pela suspensão ou separação da origem com a atualidade. E quando o filósofo aborda questões inerentes à teoria literária, também utiliza o termo "contemporâneo", modo pelo qual nos aproxima de um texto ou um autor, que vive uma relação intempestiva com o seu tempo, a exemplo de Dante.

\section{Considerações finais}

A Comédia dantesca é extraordinária e moderna, seja pela inventividade de suas inúmeras cenas ou pelos sentimentos que fazem menção ao conceito do bem e do mal. Os que são sensíveis à literatura, não permanecem indiferentes ao discurso inicial de Dante, que se diz perdido em uma "selva escura", que poderia representar uma metáfora ou um convite ao conhecimento e ao saber. Nessa grande trama encontra-se o vestígio da história, os rastros de personagens e o reflexo dessa escritura, porque o discurso literário não é hermético, mas é tecido e perpassado por fragmentos e indícios.

Daí reitera-se a contemporaneidade em Dante, porque seu poema alcançou o que Agamben define como, ruptura e soldagem do tempo, uma ligação e separação não cronológica, mas identificada pelas particularidades e descontinuidades. Se o contemporâneo exige a experiência de algo que não foi vivido, a "arqueologia que se remonta próxima da recordação e do esquecimento, é a única via de acesso ao presente", afirma Giorgio Agamben (2008, p. 139).

Assim sendo, poder-se-ia dizer que a via de acesso à Divina Comédia são esses pontos de insurgência, as assinaturas que não cessam de operar sobre o nosso tempo.

\section{Referências}

AGAMBEN, Giorgio. O que é contemporâneo? e outros ensaios. Tradução de Vinicios Nicastro Honesko. Chapecó, SC: Argos, 2009.

. Signatura Rerum: sul metodo. Torino: Bollati Boringhieri, 2008.

ALIGHIERI, Divina Comédia. Tradução de Ítalo Eugenio Mauro. São Paulo: Ed. 34, 1998.

ASSIS, Machado de. Obra completa em três volumes. Rio de Janeiro, Nova Aguilar, 1997. v. III. 
AUERBACH, Erich. Dante, o Poeta do Mundo Secular. Tradução de Raul de Sá Barbosa. Rio de Janeiro: Topbooks, 1997.

BOSI, Alfredo. O ser e o tempo da poesia. São Paulo: Cultrix; USP, 1977.

BORGES, Jorge Luis. Nove Ensaios Dantescos. In: Obras Completas de Jorge Luis Borges. São Paulo: Globo, 2000, v. III.

CACCIARI, Massimo. Nomes de lugar: Confim. Revista de Letras, São Paulo, v. 45, n. 1, p. 13-22, 2005.

CROCE, Benedetto. La Poesia di Dante. Bari: Laterza, 1948.

FALLANI, Giovanni. L’Esperienza Teologica di Dante. Lecce: Milella, 1976.

FALLANI, Giovanni; MAGGI, Nicola; ZENNARO, Silvio. Tutte le Opere. Roma: Newton e Compton Editori, 1993.

FOUCAULT, Michel. As palavras e as coisas: uma arqueologia das ciências humanas. Tradução de Salma Tannus Muchail. 9. ed. São Paulo: Martins Fontes, 2010.

. A arqueologia do saber. Tradução de Luiz Felipe Baeta Neves. 8. ed. Rio de Janeiro: Forense-Universitária, 2014.

SAPEGNO, Natalino. Compendi e Storia della Letteratura Italiana. Nuova Italia: 1986, v. I.

\section{Signatures that emerge from the dantesque Comedy}

Abstract: Agamben Giorgio, in elaborating the book Signatura Rerum (2008), affirms that it is possible to investigate the past, to arrive at the paradigm, defined as an analogical knowledge. Agamben also talks about the signature, the language of the world, from which one perceives the inner spirit of things in its exteriority, in addition to defining philosophical archeology, at a time when knowledge and discourse are constituted. Michel Foucault, the Italian philosopher, argues that "archeology is the science of ruins, practice, which investigates history not by origin, but as the emergence of the phenomenon." (AGAMBEN, 2008, p. 121). In this case, phenomena and signs emerge as examples of the Divine Comedy, from the poem, emerge characters from greek mythology, philosophers and poets, among them mantuano Virgilio, and other characters. These singularities identified in the Comedy are objects for a possible intertwining with Agamben's concept of signature.

Keywords: Literature. Divine Comedy. Archeology. Sign. Signature.

Recebido em: 25/09/2017

Aprovado em: 04/10/2017

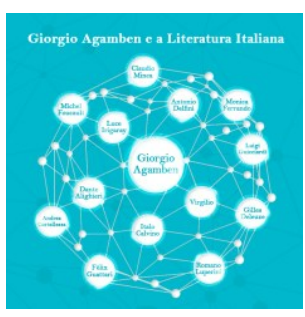

